УДК 796.88.012.015.52:796.071.2-055.1

DOI https://doi.org/10.26661/2663-5925-2021-1-24

\title{
ВПЛИВ ЗАНЯТЬ АТЛЕТИЧНОЮ ГІМНАСТИКОЮ НА ФІЗИЧНИЙ СТАН ЧОЛОВІКІВ РІЗНИХ ВІКОВИХ ГРУП
}

\author{
Симонік А. В. \\ кандидат біологічних наук, \\ дочент кафедри фізичної культури і спорту \\ Запорізький національний університет \\ вул. Жуковського, 66, Запоріжжя, Україна \\ orcid.org/0000-0001-8574-8744 \\ 020190@ukr.net
}

Пономарьов В. О.

кандидат педагогічних наук, доцент кафедри фізичної культури і спорту

Запорізький національний університет вул. Жуковського, 66, Запоріжжя, Украӥна orcid.org/0000-0001-7289-1007 cach02061977@gmail.com

Симонік М. С.

магістр кафедри фізичної культури і спорту

Запорізький національний університет

вул. Жуковського, 66, Запоріжжя, Украӥна

orcid.org/0000-0001-5412-3691

symonik90@ukr.net

Ключові слова: вікові групи, атлетичні гімнастика, фізична підготовленість, фізичний розвиток, функиіональний стан, психомоторика.
У статті розглянуто особливості впливу занять силової спрямованості на показники фізичного розвитку, функціонального стану, фізичної підготовленості та психомоторики чоловіків різних вікових груп. У дослідженні взяло участь 27 спортсменів, віком від 16 до 45 років, які були розділені на 3 групи: 1 група - 16-25 років $(\mathrm{n}=9), 2$ група 26-35 років $(\mathrm{n}=9), 3$ група $-36-45$ років $(\mathrm{n}=9)$. Вплив застосовуваних засобів підготовки оцінювався через 4 місяці.

Для визначення рухової готовності застосовували вправи: жим штанги лежачи на горизонтальній лаві, присідання зі штангою в тренажері Смітта, станова тяга; гнучкість оцінювалася за результатами нахилу з положення стоячи на лаві в сантиметрах; локальна витривалість м'язів живота оцінювалася за результатами рухового тесту підйом тулуба з положення лежачи. Для визначення функціонального стану використовувалися такі тести: проба Штанге; індекс Гарвардського степ-тесту; ЖЄЛ; життєвий індекс. Оцінку психомоторики проводили за тестами: проба Ромберга; оцінка відмінностей у масі штанги (жим з пов'язкою на очах), шкала самооцінки за Спілбергом і тепінг-тест. Для оцінки рівня фізичного розвитку ми використовували показники: вимірювання обхватів (грудної клітини, стегна, плеча, таліі); зважування; вимірювання зросту; розраховувався індекс Кетле.

Ми дослідили особливості впливу занять атлетичною гімнастикою на чоловіків різних вікових груп: 1 група - 16-25 років $(\mathrm{n}=9), 2$ група 26-35 років $(\mathrm{n}=9), 3$ група - 36-45 років $(\mathrm{n}=9)$. У таблиці 1 представлені результати проведеного дослідження. 
Ми дійшли висновку, що 3 віком показники фізичного розвитку (індекс Кетле, окружність грудей, окружність талії) зростають. Обсяг стегна, окружність плеча з віком практично не змінюються. Показники функціонального стану (індекс Гарвардського степ-тесту й життєвий індекс) знижуються з віком. Значення показників життєвої ємкості легень і проби Штанге найвищі в другій віковій групі (26-35 років). Показники спеціальної фізичної підготовки найвищі в другій віковій групі (26-35 років). Локальна витривалість м'язів живота й показник вправи «станова тяга» досягають найвищих значень у першій віковій групі (16-25 років) і з віком знижуються. Показники психомоторики учасників дослідження досягають найвищих значень у другій віковій групі (26-35 років) і незначно знижуються 3 віком. Визначення ваги штанги за рахунок м'язового відчуття найкраще розвинене в першій віковій групі (16-25 років).

Показники фізичного розвитку найчастіше змінюються в першій віковій групі. Дані, що відображають функціональний стан, найбільше змінилися в чоловіків другої вікової групи, (індекс Гарвардського стептесту). Найбільш значні зміни в руховій підготовленості досягнуті чоловіками третього віку (36-45 років). При оцінці психомоторики найбільш позитивні зміни відбулися в учасників дослідження у віці від 16 до 25 років.

Перспективи подальшого дослідження вбачаються в розробці методики підготовки спортсменів, які спеціалізуються в атлетичній гімнастиці, 3 урахуванням типу статури.

\title{
INFLUENCE OF ATHLETIC GYMNASTICS ON THE PHYSICAL CONDITION OF MEN OF DIFFERENT AGE GROUPS
}

\author{
Symonik A. V. \\ Candidate of Biological Sciences, \\ Associate Professor at the Department of Physical Culture and Sports \\ Zaporizhzhia National University \\ Zhukovskoho str., 66, Zaporizhzhia, Ukraine \\ orcid.org/0000-0001-8574-8744 \\ 020190@ukr.net \\ Ponomarov V. O. \\ Candidate of Pedagogical Sciences, \\ Associate Professor at the Department of Physical Culture and Sports \\ Zaporizhzhia National University \\ Zhukovskoho str., 66, Zaporizhzhia, Ukraine \\ orcid.org/0000-0001-7289-1007 \\ cach02061977@gmail.com
}

Symonik M. S.

Master at the Department of Physical Culture and Sports

Zaporizhzhia National University

Zhukovskoho str., 66, Zaporizhzhia, Ukraine

orcid.org/0000-0001-5412-3691

symonik90@ukr.net 
Key words: age groups, athletic Gymnastics, physical fitness, physical development, functional state, psychomotor skills.
The article considers the features of the influence of strength training on indicators of physical development, functional state, physical fitness and psychomotor skills of men of different age groups. The study involved 27 athletes aged 16 to 45 years, who were divided into 3 groups: Group $1-16-25$ years $(\mathrm{n}=9)$, Group $2-26-35$ years $(\mathrm{n}=9)$, Group $3-$ $36-45$ years $(n=9)$. The impact of the training tools used was evaluated after 4 months.

To determine motor readiness, the following exercises were used: bench press on a horizontal bench, squats with a barbell in the Smith simulator, deadlift; flexibility was evaluated by the results of tilting from a standing position on the bench in centimeters; local endurance of the abdominal muscles was evaluated by the results of the motor test lifting the torso from a lying position. The following tests were used to determine the functional state: barbell test; Harvard step test Index; vel; Life Index. Assessment of psychomotor skills was carried out according to the following tests: Romberg test; assessment of differences in barbell weight (blindfold press), Spielberg self-assessment scale, and tapping test. To assess the level of physical development, we used the following indicators: measurement of girths (chest, hip, shoulder, waist); weighing; height measurement; the Quetelet index was calculated.

We investigated the impact of athletic Gymnastics on men of different age groups: Group $1-16-25$ years $(n=9)$, Group $2-26-35$ years $(n=9)$, Group 3-36-45 years $(n=9)$. Table 1 shows the results of the study.

We came to the conclusion that with age, indicators of physical development (Quetelet Index, chest circumference, waist circumference) increase. Hip volume and shoulder circumference practically do not change with age. Indicators of functional status (Harvard step test index and vital index) decrease with age. The values of indicators of vital capacity of the lungs and the barbell test are the highest in the second age group (26-35 years). Indicators of special physical fitness are the highest in the second age group (26-35 years). Local endurance of the abdominal muscles and the indicator of the "deadlift" exercise reach the highest values in the first age group (16-25 years) and decrease with age. Indicators of psychomotor skills of the study participants reach the highest values in the second age group (26-35 years) and slightly decrease with age. Determining the weight of a barbell due to muscle sensation is best developed in the first age group (16-25 years).

Indicators of physical development most often change in the first age group. Data reflecting functional status changed the most in men in the second age group (Harvard step test index). The most significant changes in motor fitness were achieved by men of the Third Age (36-45 years). When assessing psychomotor skills, the most positive changes occurred in study participants aged 16 to 25 years.

Prospects for further research are seen in the development of methods for training athletes specializing in athletic Gymnastics, taking into account the body type.
Постановка проблеми. Атлетична гімнастика набула широкого розповсюдження як в Україні, так і в усьому світі, за межами нашої країни. Система вправ на опір, спрямованих на збільшення м'язової маси, більш відома як бодібілдинг. Якщо бодібілдинг як вид спорту викликає певні суперечливості, то той факт, що атлетична гімнастика є одним із найпопулярніших видів фізичної культури, не викликає сумнівів. Підтвердженням цього є відкриття нових фітнес-центрів, клубів 3 бодібілдингу, спортзалів, які охоплюють усе більш широкі верстви населення, і їх відвідування дуже популярно. При цьому основним мотивом $\epsilon$ вдосконалення статури й розвиток сили. Крім оздоровчої функції, спортивна гімнастика має естетичні та реабілітаційні функції.

Аналіз останніх досліджень і публікацій. Іноземні автори при побудові тренувальних курсів відзначають важливість індивідуалізації тренувального процесу в атлетичній гімнастиці $[1 ; 2 ; 3]$. В опублікованих роботах мова йде про використання різних дієт і спеціального спортив- 
ного харчування, що враховують конституційні особливості спортсменів [1; 2]. Існує безліч тренувальних програм, які враховують вік та особистісні здібності.

Наявні у вітчизняній літературі дані про індивідуалізацію тренувального процесу в умовах масової атлетичної гімнастики недостатньо розкривають технологію побудови тренувального процесу 3 урахуванням вікових і конституціональних особливостей, хоча багато досліджень присвячені вивченню проблем вдосконалення статури й розвитку сили [4].

У зв'язку із цим метою дослідження стала розробка програми силових тренувань з урахуванням типу статури чоловіків віком від 16 до 45 років.

Методи й організація дослідження. У дослідженні взяло участь 27 спортсменів, віком від 16 до 45 років. Учасники були поділені відповідно до вікових груп, по 9 осіб у кожній групі (16-25, 26-35 і 36-45 років).

Педагогічні тести проводилися на початку й у кінці педагогічного дослідження (через 4 місяці занять) 3 метою отримання характеристик різних аспектів підготовки.

Тести проводилися 3 використанням уніфікованих комплексних тестів, що оцінюють фізичну підготовленість. Аналіз літературних даних показав $[5 ; 6]$, що в результаті силових вправ адаптаційним змінам піддаються передусім серцево-дихальна, нервово-м'язова системи організму й моторно-психічна сфера.

Для визначення функціонального стану використовувалися такі тести: проба Штанге; індекс Гарвардського степ-тесту; ЖЄЛ; життєвий індекс.

ПробаШтанге - функціональна проба із затримкою дихання під час вдиху для оцінки дихальної функції. Проба дає змогу оцінювати гіпоксичні здібності (стійкість організму до гіпоксії).

Аеробна продуктивність оцінена за допомогою тесту кроку Гарвардського степ-тесту.

За результатами спірометрії оцінювали життєву ємкість легень, для цього використовували сухий спірометр.

Життєвий індекс визначався розрахунковим шляхом за формулою:

$$
E^{2}=\frac{A^{a} \ddot{E}}{\grave{I}},
$$

де ЖІ - життєвий індекс (мл/кг); ЖЄЛ життєва ємкість легень (мл); М - вага (кг).

Примітно, що показники психомоторики мають найбільшу вагу в структурі силового тренування. Учені вважають, що спортсмени в силових видах спорту мають виражені низькі пороги чутливості в різних аналітичних системах. Ці пороги можуть бути залежними від виду спорту. Таким чином, у більшості важкоатлетів розвинене почуття рівноваги, дуже добре розвинене пропріоцептивне м'язове відчуття. У зв'язку з подібністю специфіки важкої атлетики та атлетичної гімнастики для оцінки психомоторики ми використовували такі тести: проба Ромберга (за 5-бальною системою); оцінка відмінностей у масі штанги (жим із пов'язкою на очах), а так само шкала самооцінки за Спілбергом і тепінг-тест.

У результаті педагогічних спостережень, узагальнення практичного досвіду тренерів, а також аналізу спеціальної методологічної літератури відібрані такі контрольні вправи для визначення рухової готовності: жим штанги лежачи на горизонтальній лаві (вимірювалася максимальна сила в кг); присідання зі штангою в тренажері Смітта (вимірювалася максимальна сила в кг); станова тяга (вимірювалася максимальна сила в кг). Гнучкість оцінювалася за результатами нахилу 3 положення стоячи на лаві в сантиметрах. Локальна витривалість м'язів живота оцінювалася за результатами рухового тесту: підйом тулуба 3 положення лежачи (фіксується кількість підйомів за хвилину).

Для визначення рівня фізичного розвитку ми використовували такі показники: вік, років; вимірювання обхватів тіла за допомогою сантиметрової стрічки (обхват грудної клітини при вдиху-видиху, визначалося середнє значення); обхвати стегна - правого, лівого; обхвати плеча - правого, лівого (використовувалося найбільше значення); обхват талії; зважування; вимірювання зросту; розраховувався індекс Кетле (ваго-ростовий Індекс).

Проводилися психологічні тести для оцінки психологічного стану. Для цього ми використовували шкалу самооцінки Спілберга, яка допомагає оцінити рівень особистої тривоги.

Психологічні тести застосовані на 2-му етані дослідження.

Отримані дані піддавалися логічному й математичному аналізу 3 апаратною обробкою на комп'ютері. Ми розрахували стандартні статистичні показники досліджуваної вибірки. Надійність отриманих даних уважалася суттєвою на рівні значущості 5\%, що є досить надійно для педагогічних досліджень.

Результати дослідження та їх обговорення. Організація тренувального процесу на заняттях атлетичною гімнастикою здійснюється шляхом підбору методів тренування відповідно до приватних завдань. 3 огляду на специфіку силових тренувальних навантажень, його методи мають свої особливості, діючи як засоби управління, і підкорюються певним закономірностям і принципам. При цьому різноманіття засобів управління тренувальним процесом безпосередньо пов'язане зі знанням фізіологічних процесів, що відбуваються 
в організмі, й особливостями сприйняття навантаження на рівні біохімічних і функціональних реакцій.

Вправи на опір призводять до певних типів пристосувань, так як силові вправи впливають тільки на обмежений набір компонентів фізичних якостей.

У вправах з використанням обтяжень розвиваються такі фізичні якості: максимальна сила, швидкість одиночного руху, витривалість до силових навантажень у різних зонах інтенсивності, міжм'язова i внутрішньом'язова координація, пасивна гнучкість, а також відбувається робоча гіпертрофія м'язової тканини.

Ми дослідили особливості впливу занять атлетичною гімнастикою на чоловіків різних вікових груп: 1 група - 16-25 років $(\mathrm{n}=9), 2$ група 26-35 років $(\mathrm{n}=9), 3$ група $-36-45$ років $(\mathrm{n}=9)$. У таблиці 1 представлені результати проведеного дослідження.

Аналізуючи отримані дані, ми дійшли висновку, що з віком показники фізичного розвитку (індекс Кетле, окружність грудей, окружність талії) зростають. Обсяг стегна, окружність плеча 3 віком практично не змінюються. Показники функціонального стану (індекс Гарвардського стептесту й життєвий індекс) знижуються 3 віком. Значення показників життєвої ємкості легень і проби Штанге найвищі в другій віковій групі (26-35 років).

Показники спеціальної фізичної підготовки найвищі в другій віковій групі (26-35 років). Локальна витривалість м'язів живота й показник вправи «станова тяга» досягають найвищих значень у першій віковій групі (16-25 років) і з віком знижуються.

Показники психомоторики учасників дослідження досягають найвищих значень у другій віковій групі (26-35 років) і незначно знижуються 3 віком. Визначення ваги штанги за рахунок м'язового відчуття найкраще розвинене в першій віковій групі (16-25 років).

Після закінчення чотирьох місяців занять нами проведене повторне визначення всіх досліджених показників. Зазначимо, що позитивні зміни

Таблиця 1

Показники фізичного стану учасників дослідження (M $\pm \mathbf{m})$

\begin{tabular}{|c|c|c|c|}
\hline Показник & $16-25$ років $(\mathrm{n}=9)$ & $26-35$ років $(\mathrm{n}=9)$ & $36-45$ років $(\mathrm{n}=9)$ \\
\hline \multicolumn{4}{|c|}{ Фізичний розвиток } \\
\hline BPI, y.o. & $425,35 \pm 28,57$ & $450 \pm 30,08$ & $473,14 \pm 21,90$ \\
\hline ОГК, см & $107,93 \pm 3,98$ & $110,88 \pm 2,98$ & $113,85 \pm 3,94$ \\
\hline Обхват стегна, см & $60,68 \pm 1,79$ & $61.5 \pm 2,50$ & $61,78 \pm 1,97$ \\
\hline Обхват плеча, см & $37,5 \pm 1,45$ & $39,44 \pm 1,67$ & $39,21 \pm 1,13$ \\
\hline Окружність талії, см & $85,18 \pm 2,85$ & $91,27 \pm 3,22$ & $97,46 \pm 3,03$ \\
\hline \multicolumn{4}{|c|}{ Функціональний стан } \\
\hline ЖЕЛ, л & $4,078 \pm 256,70$ & $4,720 \pm 202,97$ & $4,405 \pm 125,36$ \\
\hline ІГСТ, у.о. & $86,66 \pm 2,26$ & $85,22 \pm 7,28$ & $81,11 \pm 3,34$ \\
\hline ЖІ, мл/кг & $65,55 \pm 3,22$ & $61,32 \pm 4,65$ & $53,55 \pm 1,79$ \\
\hline Проба Штанге, с & $71,66 \pm 7,87$ & $78,22 \pm 5,78$ & $69,11 \pm 5,25$ \\
\hline \multicolumn{4}{|c|}{ Фізична підготовленість } \\
\hline Оцінка гнучкості, см & $8,57 \pm 1,21$ & $9,37 \pm 1,65$ & $10,05 \pm 2,32$ \\
\hline $\begin{array}{c}\text { Локальна витривалість м’язів } \\
\text { живота, разів/хв }\end{array}$ & $43,37 \pm 1,85$ & $42,77 \pm 1,31$ & $41,71 \pm 2,72$ \\
\hline Жим штанги лежачи, кг & $89,37 \pm 15,94$ & $92,77 \pm 9,54$ & $87,14 \pm 9,10$ \\
\hline Станова тяга, кг & $131,87 \pm 19,93$ & $127,77 \pm 17,90$ & $118,57 \pm 12,90$ \\
\hline $\begin{array}{c}\text { Присідання в тренажері Сміт- } \\
\text { та, кг }\end{array}$ & $103,75 \pm 13,95$ & $118,88 \pm 14,92$ & $109,28 \pm 12,13$ \\
\hline \multicolumn{4}{|c|}{ Психомоторика } \\
\hline Оцінка проби Ромберга, с & $4,12 \pm 0,13$ & $4,22 \pm 0,11$ & $4,14 \pm 0,15$ \\
\hline $\begin{array}{c}\text { Шкала самооцінки (Спілберг), } \\
\text { у.о. }\end{array}$ & $38,62 \pm 2,39$ & $40,22 \pm 2,14$ & $39,85 \pm 1,36$ \\
\hline $\begin{array}{c}\text { Визначення ваги штанги за } \\
\text { рахунок м’язового відчуття, } \\
\text { відхилення }\end{array}$ & $7,5 \pm 1,99$ & $10 \pm 1,79$ & $9,28 \pm 1,51$ \\
\hline Тепінг-тест, к-ть точок & $68,87 \pm 1,72$ & $71,66 \pm 1,79$ & $68,28 \pm 1,51$ \\
\hline
\end{tabular}

Примітка: ВРІ - вагоростовий індекс, ОГК - окружність грудної клітини, ЖЕЛ-життєва ємкість легень, ІГСТ - індекс Гарвардського степ- 


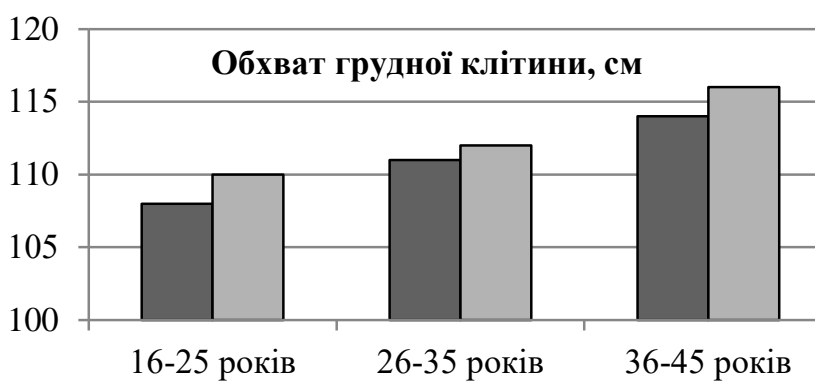

口Початок $\square$ Завершення

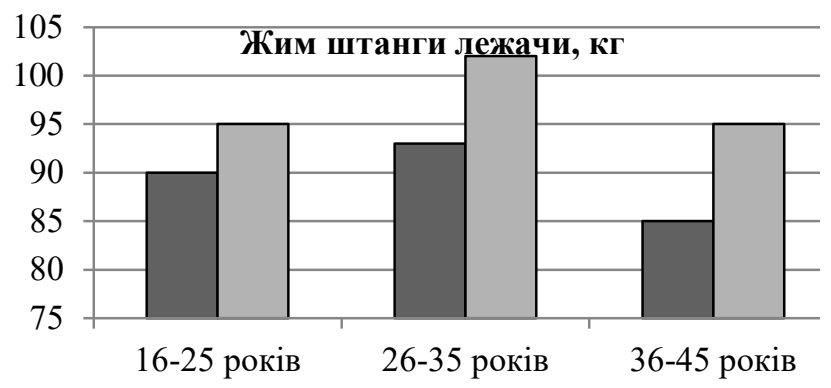

$\square$ Початок $\square$ Завершення

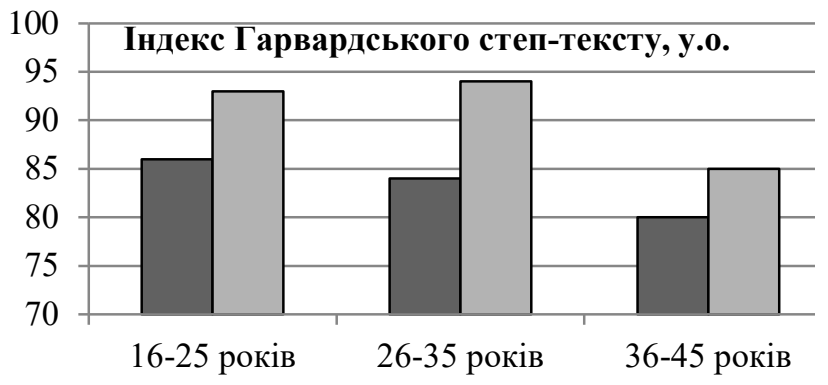

口Початок $\square$ Завершення

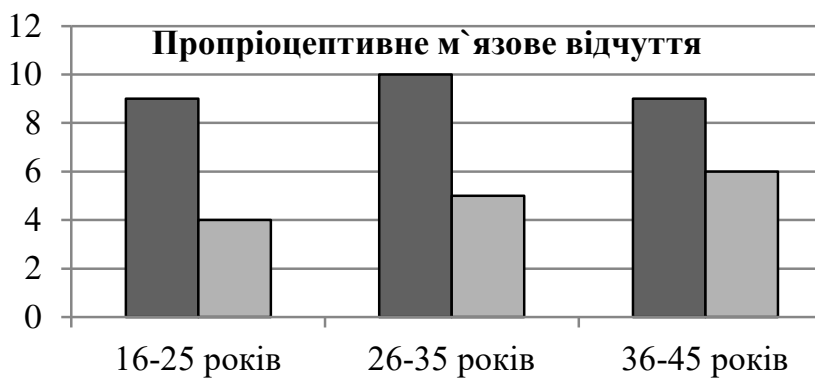

口Початок $\square$ Завершення

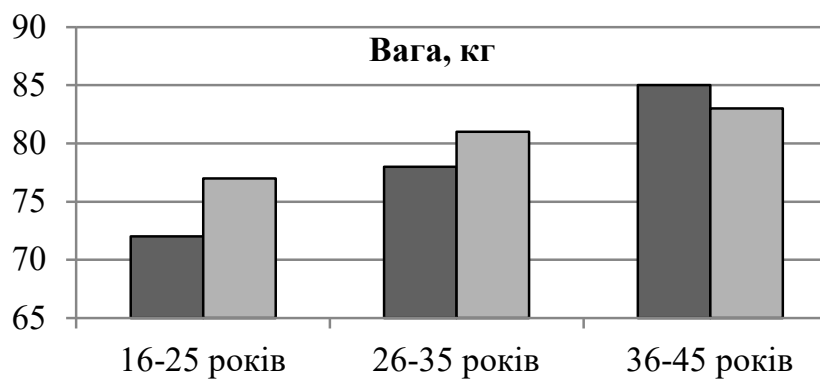

$\square$ Початок $\square$ Завершення

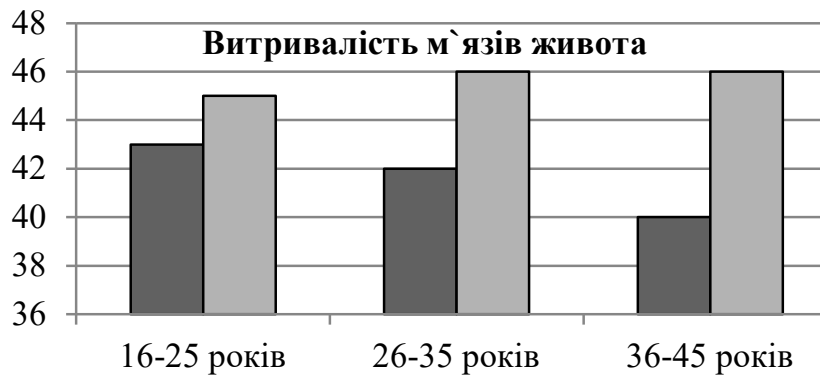

$\square$ Початок $\square$ Завершення

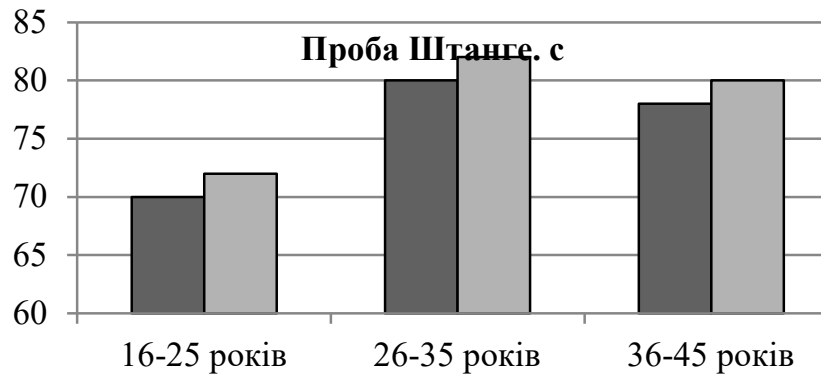

$\square$ Початок $\square$ Завершення

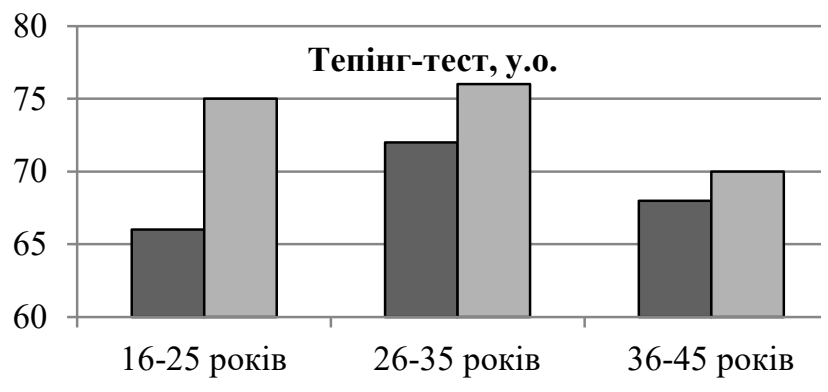

$\square$ Початок $\square$ Завершення

Рис. 1. Динаміка показників фізичного розвитку, функціонального стану, фізичної підготовленості та психомоторики чоловіків різних вікових груп

відбулися за показниками фізичного розвитку: об'єм грудної клітини, вага; функціонального стану - індекс Гарвардського степ-тесту, проба
Штанге; рухової підготовленості - жим штанги лежачи, локальна витривалість м'язів живота; психомоторики - пропріоцептивне м'язове 
почуття (визначення ваги штанги завдяки мязовому відчуттю).

У чоловіків 16-25 років показники фізичного та психомоторного розвитку були найбільш схильні до змін. У другій віковій групі (26-35 років) найбільше змінилися дані, що відображають функціональний стан, але отримані дані ненадійні (p>0,05). У чоловіків третьої вікової групи (36-45 років) найбільші зміни були зареєстровані в руховій підготовленості.

Оскільки дані, отримані в результаті експерименту, ненадійні (p > 0,05), за винятком показників психомоторики й рухової підготовленості, при плануванні тренувального процесу необхідно звертати увагу на зміни показників фізичного стану, що відбуваються з віком.

3 вищесказаного можна зробити висновок, що заняття атлетичною гімнастикою з точки зору оцінки фізичної підготовленості не впливає однаково на чоловіків різного віку.

Висновки. Аналіз науково-методичної літератури показав, що індивідуалізація тренувального процесу в умовах масової спортивної гімнастики недостатньо розкриває технологію побудови тренувального процесу з урахуванням вікових i конституціональних особливостей, хоча багато досліджень присвячені вивченню проблем вдосконалення статури й розвитку сили.

Вивчення особливостей впливу занять атлетичною гімнастикою на фізичний стан чоловіків різного віку показало, що показники фізичного розвитку найчастіше змінюються в першій віковій групі (16-25 років). Окружність грудної клітини збільшилася в середньому на 3 см, вага збільшилася на 3,95 кг. Дані, що відображають функціональний стан, найбільше змінилися в чоловіків другої вікової групи (26-35 років), значення індексу Гарвардського степ-тесту збільшилася на 7,55 у.о., показник проби Штанге збільшилася на 7,11 секунди. Найбільш значні зміни в руховій підготовленості досягнуті чоловіками третього віку (36-45 років). Середня величина вправи «жим штанги лежачи» збільшилася на 13,89 кг, локальна витривалість м'язів живота збільшилася на 6,22 (кількість разів). При оцінці психомоторики найбільш позитивні зміни відбулися в учасників дослідження у віці від 16 до 25 років. Пропріоцептивне м'язове відчуття покращилося на 4,45 кг, а оцінка тепінг-тесту збільшилася на 8,33 (кількість балів).

\section{ЛІТЕРАТУРА}

1. Helms E.R., Aragon A.A., Fitschen, P.J. Evidence-based recommendations for natural bodybuilding contest preparation: nutrition and supplementation. J Int Soc Sports Nutr. 2014. № 11. P. 20. URL: https://doi. org/10.1186/1550-2783-11-20.

2. Lambert C.P., Frank L.L., Evans W.J. Macronutrient Considerations for the Sport of Bodybuilding. Sports Med. 2004. № 34. P. 317-327. URL: https://doi.org/10.2165/00007256-200434050-00004.

3. Olivia C., Potop V., Cheran C. Development of muscle strength by using basic and complementary exercises in bodybuilding for masses timnea. Science, Movement and Health. 2013. Vol. XIII. № 13 (2). P. 362-368.

4. Smith A.C.T., Stewart B. Body Perceptions and Health Behaviors in an Online Bodybuilding Community. Qualitative Health Research. 2012. № M22(7). P. 971-985

5. Lachlan Mitchell, Gary Slater, Daniel Hackett, Nathan Johnson \& Helen O'connor. Physiological implications of preparing for a natural male bodybuilding competition, European Journal of Sport Science. 2018. № 18:5. P. 619-629.

6. Steele, Ian H. MD; Pope, Harrison G. Jr. MD; Kanayama, Gen MD, PhD Competitive Bodybuilding: Fitness, Pathology, or Both? Harvard Review of Psychiatry. 2019. № 7/8. Volume 27. Issue 4. P. 233-240. 